\title{
A Review of Recent Provenance Studies from the Ghaggar-Hakra-Nara Alluvium: Link to the Lost River of the Harappan Civilization
}

\author{
ANIRBAN CHATTERJEE ${ }^{1, *}$ \\ ${ }^{1}$ Department of Geology, Presidency University, Kolkata, India
}

(Received on 18 July 2017; Revised on 14 February 2019; Accepted on 16 August 2019)

\begin{abstract}
Numerous ruins of the Bronze Age Harappan settlements can be found along the present-day dry channels of the GhaggarHakra-Nara river system of the western Indian sub-continent. The river has often been correlated to the mythological river Saraswati of Rig-Veda due to its matching geographical position with the former. The archaeological connection prompted many workers to hypothesise that the Ghaggar-Hakra was a mega river system during the recent past. However, the nature of the river during the Harappan period remained debated. Although several mega paleo-channels are identified by satellite imageries along the Ghaggar-Hakra river, their activity during Holocene, remained a conjecture until recently due to insufficient geochronological and geochemical data. Combined geochronological and geochemical studies of the GhaggarHakra-Nara alluvium have finally started to reveal the evolution of the river system over the geologic past. This review will discuss our present understanding of the long-debated topic under the light of geochemical sediment provenance and geochronological studies and try to shed some light on the future possibilities to fill the gaps in the story.
\end{abstract}

Keywords: Holocene; Ghaggar-Hakra-Nara alluvium; Sediment Provenance; Saraswati; Geochemistry; Great Rann of Kachchh

\section{Introduction}

The Ghaggar-Hakra River of the north-west Indian subcontinent is mostly a defunct small stream which originates in the Siwalik Himalayas (Fig. 1). It seasonally gets flooded during the high monsoonal rains and carries suspended sediments, reworked from older interfluve deposits (Singh et al., 2016). Further downstream, the dry river-bed, known as the Hakra vanishes in the Cholistan desert of Pakistan. Towards south, another defunct channel known as the Nara river,drainsinto the Great Rann of Kachchh (Fig. 1). Ghaggar-Hakra is rather one of those numerous foothill-fed rivers (Sinha and Friend, 1994) which flows in the interfluves between the mighty glacier-fed rivers of the vast Indo-Gangetic plains. Yet, this small river has attracted a lot of scientific attention due to its unique geological past and archaeological connection. The dry river beds were speculated to be the relicts of a glacier fed paleo-river and often been correlated with the mythical lost river Saraswati, first described in the three millennia old scriptures of Rig-Veda due to its matching geographical position with the latter (Oldham, 1893; Ghose et al., 1979; Pal et al., 1980; Radhakrishan and Merh, 1999; Kochar, 2000; Valdiya, 2013). The search for the lost river of the Indian desert goes back to at least two centuries, when British geographers were surveying their newly occupied colony. C. F. Oldham first traced the dry beds and proposed that Sutlej might had been flowing through the Ghaggar channel during historic times (Oldham, 1893). It was hypothesised that the Ghaggar-HakraNara used to be an independent river system flowing parallelto the Indus all the way down to Arabian Sea (Glennie and Evans, 1976).

With the discovery of the Bronze Age Harappan civilisation, the scenario became more intriguing. Years of archaeological excavations revealed that, apart from the Indus River valley, a great majority of Harappan settlements were concentrated along the Ghaggar-Hakra (Stein, 1942). As water availability is one of the major requisites for any civilisation, archaeologists have considered that the ephemeral

*Author for Correspondence: E-mail: anirban.geol@presiuniv.ac.in; myworld.anirban@gmail.com 


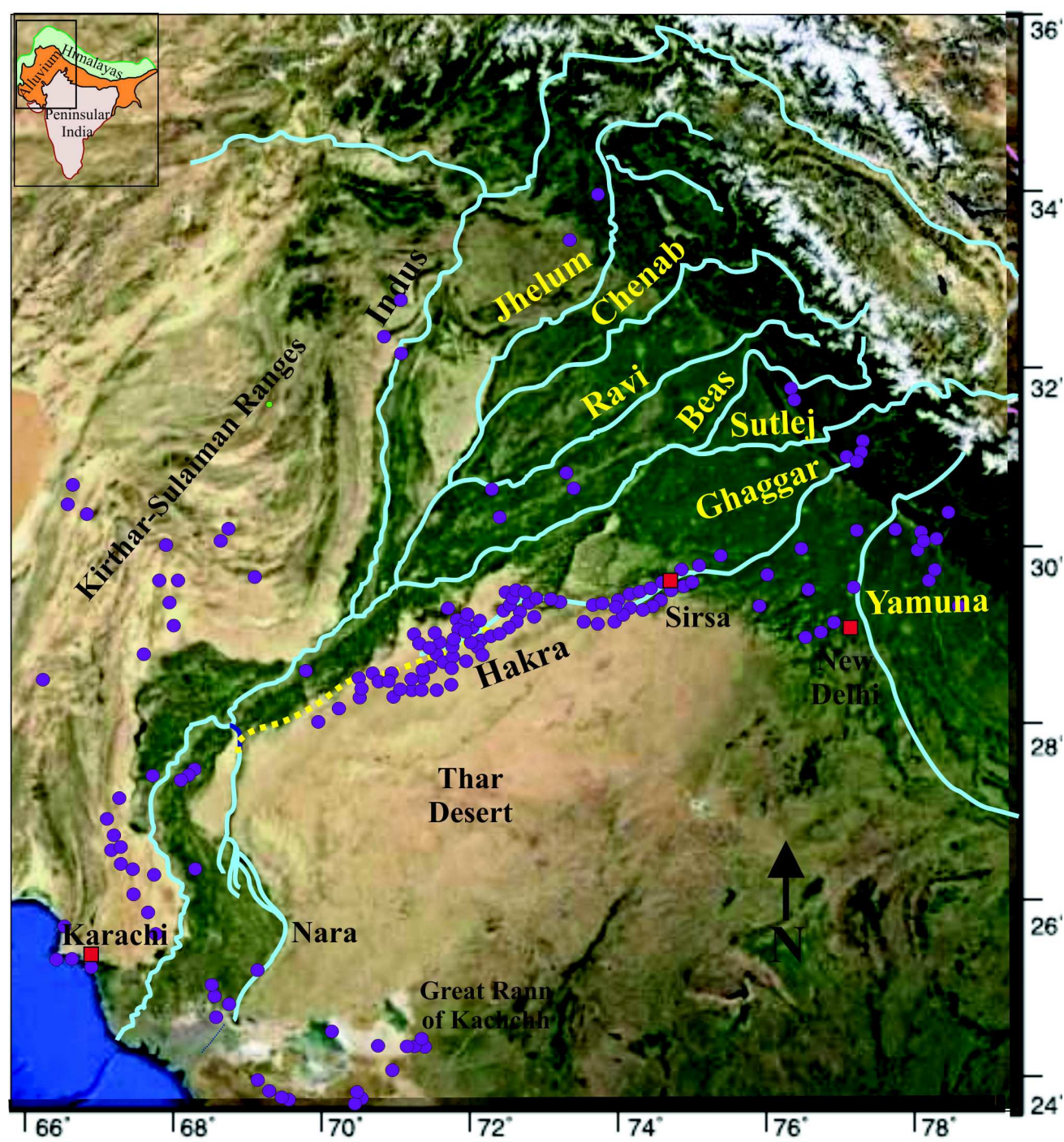

Fig. 1: The Google Earth image of North-western Indian sub-continent with the river systems traced with blue lines. The yellow dotted line connecting the Ghaggar-Hakra channel with the Nara is the proposed channel of the lost river which is buried under the desert dunes. The purple dots are the locations (Danino, 2010) of Harappan sites (inclusive of all the phases)

Ghaggar-Hakra stream must had a more reliable flow during the pre-historic time of the Harappans (Valdiya, 2017). Several workers have suggested that the drying up of the Ghaggar-Hakra River could be a triggering factor for the sudden decline of the Harappan civilisation in this part of the country, four millennia ago (Mughal, 1997; Possehl, 2002; Kenoyer, 2008; Wright et al., 2008).

The following centuries saw a plethora of scientific investigations in the Ghaggar valley. With the advancement of satellite imagery based studies, there was a rapid progress on the search for the lost river. Works based on satellite imageries have confirmed the existence of several palaeo-channels of an earlier mega-river system along the GhaggarHakra flood-plains extending up to the Great Rann of Kachchh in the south (Ghose et al., 1979; Gupta et $a l ., 2011)$. It is considered by many that the transformation of once mighty river during the recent past (mid-Holocene) was due to regional reorganisations of major Himalayan Rivers induced by neo-tectonics and the river piracy associated with it (Sutlej and Yamuna getting diverted from the Ghaggar channel). Until this point, all the puzzle pieces seemed to fit properly in the story of the lost river of 
Indian desert. But debates don't cease to surround this forgotten river and its pre-historic civilization. Inadequate geochemical and geochronological data made it difficult to constrain the true nature of the paleo river and the exact period of its demise.

In recent years attempts have been made to understand the evolution of the river by studying the sediment provenance and depositional ages of the alluvium. The outcomes of these studies however, have conflicting conclusions. Competing hypotheses consider that the startling geomorphic change of the Ghaggar river valley have occurred much earlier, during theLate Pleistocene (at least before $10 \mathrm{ka}$ ) and the channels got abandoned during 4-5ka ago (Clift et al., 2012). These studies indicated that the river had glacial connections before Holocene and it transformed intoa foothill-fed monsoonal river by the time humans first settled on its banks (Tripathi et al., 2004; Clift et al., 2012; Giosan et al., 2012). Contrary to this hypothesis, younger fluvial activities (2.9-0.7 ka) have been reported both from upper and lower Ghaggar-Hakra-Nara floodplains (Saini et al., 2009; Giosan et al., 2012). Also, recent work has shown that the Ghaggar-Hakra-Nara was a continuous channel until recently $(\sim 1 \mathrm{ka})$ even though it was an ephemeral river during that time (Chatterjee and Ray, 2017; Chatterjee, 2017). A meandering river system frequently changes its course and creates numerous abandoned channels. Therefore, depositional ages of sediments from only a few sections may not reveal the true temporal extent of the river (Valdiya, 2013). Thus, at present the problem regarding the paleo-fluvial condition of the Ghaggar river and its archaeological connection is far from getting solved.

The main aim of this article is to review the recent findings regarding the sediment provenance and depositional ages of Ghaggar-Hakra-Nara alluvium, to better understand the evolutionary history of the river. But before delving in to the provenance studies we will first discuss a brief history of human settlements along the Ghaggar valley and the time frame of the evolution of Harappan civilisation. This on the other hand will shed some light on the Harappan Civilisation-Ghaggar river connection. We will look into the lost river problem by focussing separately at the three segments of the relict river beds (i.e., Ghaggar. Hakra andNara).

\section{A Brief History of Harappan Civilisation Settlements along the Ghaggar River}

The Indus Valley/Harappan cultural tradition flourished along the North-western margin of the Indian subcontinent during mid-Holocene (Fig. 1). Their total settlement area was much larger than the contemporaneous civilisations of Mesopotamia and Egypt. The evolution period of this culture, based on chronologies from and around the nearby localities of Harappa have been divided into four phases/periods (Kenoyer, 1998; Wright et al., 2008; Dikshit, 2013). The agro-pastoral Ravi culture flourished around 5.7 ka. This was followed by the transitional Kot Diji Phase $(\sim 4.8 \mathrm{ka})$. Around $4.6 \mathrm{ka}$ the sophisticated urban civilization of the Mature Harappan phase began. The urbanised phase disintegrated at $\sim 3$.9ka. This was followed by the Late Harappan phase of deurbanisation era. The de-urbanisation era lasted until $\sim 3.3 \mathrm{ka}$. Based on spatio-temporal distribution of archaeological remains that spread across the Indian sub-continent, Possehl (2002) proposed an older age for the Harrapan culture. Such older pre-Harappan settlements along the Hakra river of Cholistan desert had been reported earlier also (Mughal, 1997). It was named as the Hakra Phase. Later, numerous other sites of the Hakra phase were discovered along the dry beds of the Ghaggar (the upstream continuation of Hakra) including Kalibangan, Farmana, Bhirrana, Rakhigarhi etc. The antiquity of the Hakra Phase can be traced back to $\sim 9.5 \mathrm{ka}$ based on available chronological information (Sarkar et al., 2016 and the references therein). Moreover, the early mature Harppan phase started $\sim 6.5 \mathrm{ka}$ in the Ghaggar-Hakra valley which was few millennia older than that of the Indus valley. Indeed, in a study on spatio-temporal evolution of Harappan settlements, Gangal et al. (2010) has demonstrated that $7 \mathrm{ka}$ onwards settlements had started flourishing in three distinct geographical locations separated from each other viz., the Baluchistan region, Ghaggar plain and the Gujarat region. Following period saw a steady increase in the settlement densities in these three localities. Surprisingly, the first settlements along the Indus river system started developing only during 5.2 ka prompting to the suggestion that the urban settlements of lower Indus-valley are the extension from the Baluchisthan and Ghaggar settlements. Finally, the civilisation reached its zenith during $4.5 \mathrm{ka} .3 .9 \mathrm{ka}$ onwards the 
de-urbanisation started and the settlement densities started decreasing in the main centres. It is observed that the Harappan settlements gradually shifted northeastward to the upper Haryana plains during this period (Gangal et al., 2010; Giosan et al., 2012).

It took few centuries for new settlements to develop along the Ghaggar valley in the post Harappan period. During 3-2.6 ka, the Ghaggar-Hakra valley was re-occupied by the people of Painted Grey Ware culture.

All these observations indicate towards a stronger fluvial past of the present day Ghaggar-Hakra river. The archaeological evidences convinced the scholars that the Ghaggar must have been a perennial river during the Harappan times unlike present day.

\section{Sedimentary Facies and Provenance of Ghaggar alluvium}

The Ghaggar River channel is very difficult to trace downstream at present, because of heavy irrigation and shallow channel chocked with heavy suspended load. The flood plain topography is monotonously flat land with aeolian dunes. The dry bed of the river can only be discretely recognised by ridges of discontinuous sand dunes bordering the floodplain. Interestingly, the subsurface sedimentary facies are quite different to what appears on the dry river bed. Figure 2 presents a comparison of the subsurface stratigraphy from different localities along the alluvium.

\section{Facies Architecture of the Ghaggar alluvium}

The topmost alluvium cover is composed of brown silty-clay of varying thickness. Just below the brown silty-clay, directly lies either a yellowish-brown fine fluvial sand horizon or a grey micaceous sand horizon. The first occurrence of a thick body of coarse micaceous grey coloured sand (resembling to the sediment carried by modern glacial rivers like Ganga, Yamuna) buried below the silty-clay layers of Ghaggar near Kalibangan was reported by Raikes (1968). From several other locations similar facies association have been reported (Saini et al., 2009; Saini and Mujtaba, 2012; Singh et al., 2016). The coarse and immature grey coloured sand probably represents bed load sediment and indicative of once active fluvial system. However, in other places these grey fluvial sands are overlain or underlain by yellowish-brown fine fluvial sands. Probably a weaker fluvial system had deposited these fine fluvial sands by reworking from the older alluvium deposits and local sand dunes.

\section{Depositional Ages of Sediments in Ghaggar alluvium}

Fluvial sediments deposited in the Ghaggar alluvium span from late Pleistocene to mid-Holocene mainly. The age constrains and sedimentation history of Ghaggar alluvium is discussed below.

Brown Silty-Clay: The OSL depositional ages of $2.9 \pm 0.2 \mathrm{ka} \mathrm{BP}$ and $3.4 \pm 0.2 \mathrm{ka} \mathrm{BP}$ for the brown silty-mud floodplain horizons, in Sirsa-Fatehbad region
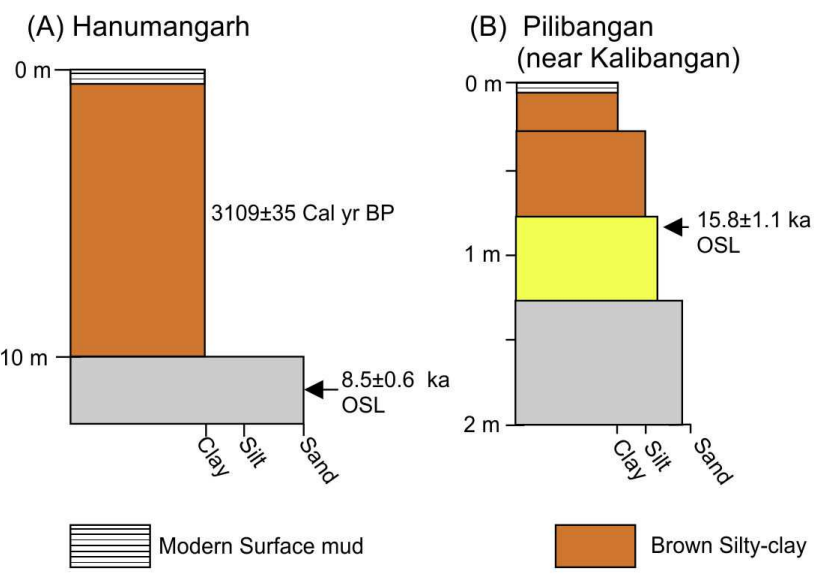

(C) Sirsa-Fatehabad-I

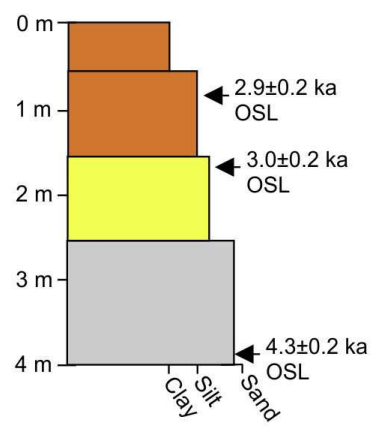

Yellowish-brown Sand
(D) Sirsa-Fatehabad-II

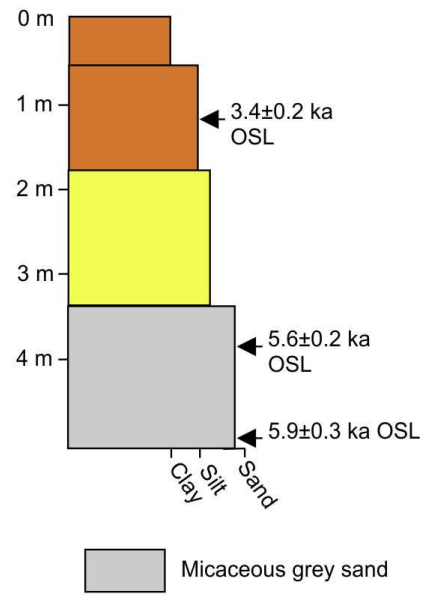

Fig. 2: The subsurface sediment horizons of the Ghaggar alluvium at (A) Hanumangarh, (B) Pilibangan and (C) SirsaFatehbad-I and (D) Sirsa-Fatehbad-II, region. Source: Saini et al. (2009), Chatterjee and Ray (2018) 
had been reported by Saini et al. (2009). Further downstream at Hanumangarh the depositional age of silty-claylayer has been estimated to be $3109 \pm 35 \mathrm{cal}$ yr BP (Chatterjee and Ray, 2018). Even today, during the monsoonal flooding the fine silty-clay sediment used to get deposited.

Grey Micaceous Sand: The underlying grey micaceous fluvial sand, on the other hand was getting deposited since the Pleistocene. Singh et al. (2016) had reported depositional age of these grey micaceous sands from Kalibangan region to be from $\sim 70$ to $\sim 20 \mathrm{ka}$. However, much younger depositional ages for the grey sand is also reported. The youngest age for the grey sand is reported to be $4.3 \pm 0.2 \mathrm{ka} \mathrm{BP}$ (Saini et al., 2009), from upstream Sirsa-Fatehbad region. Further downstream, the depositional age of the grey sand at Hanumangarh is $8.5 \pm 0.6 \mathrm{ka} \mathrm{BP}$ (Chatterjee and Ray, 2016; Chatterjee and Ray, 2018).

Yellowish Brown Sand: This particular facies was getting deposited during 14-20ka (Saini et al., 2009). Near Pilibanga the depositional age is $15.8 \pm 1.1$ ka BP (Chatterjee and Ray, 2018). However, Saini et al. (2009) have reported much younger depositional age of this facies. At the upstream Sirsa region the depositional age is $\sim 3 \mathrm{ka}$.

The facies architecture and ages indicate that there were fluctuations in fluvial activity multiple times in the Ghaggar floodplain. It appears that a much stronger fluvial system of past has gradually reduced into a dwindling meandering system during the Holocene. During the latter phase other plain-fed tributaries of the river started dominating the floodplain depositions (weaker system, thus finer sediments). Based on sedimentary architecture and depositional ages along the Ghaggar alluvium, several paleochannels belonging to different period has been re-constructed (Fig. 3). However, their upstream or downstream continuation of these channels is still debated. For proper characterization of the sediment sources and to understand the depositional pathways, the geochemical properties of these sediments along the Ghaggar flood plain have to be characterised.

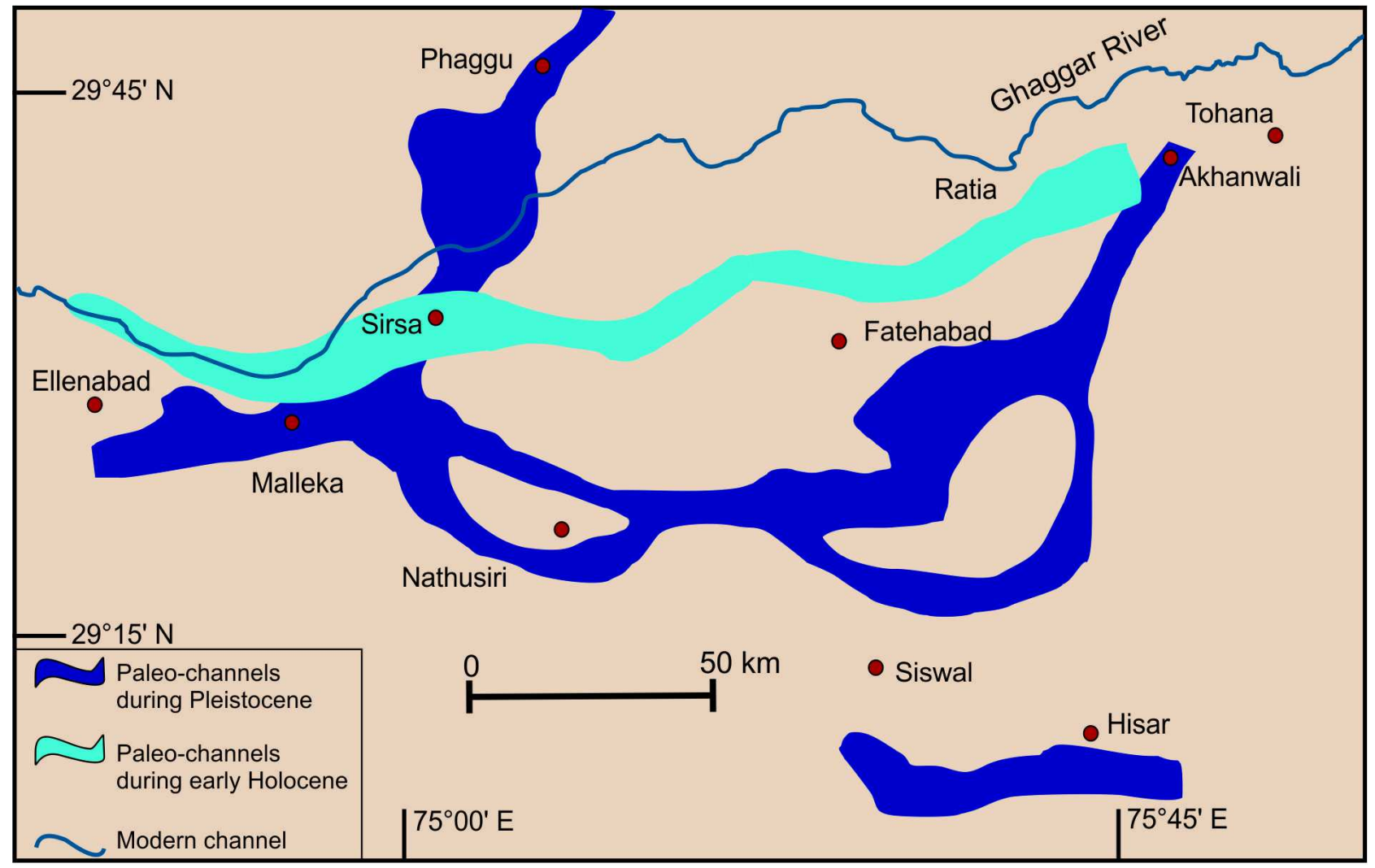

Fig. 3: The reconstructed paleo-channels of Ghaggar during the Pleistocene and Holocene period near Sirsa-Fatehbad region (modified from Saini et al., 2009) 


\section{Provenance Study of Ghaggar Sediments: Sr-Nd iIotopic Fingerprinting}

Deciphering the provenance of sediments derived from multiple sources is a complex affair. In order to correctly identify the sources, it is essential to know the character of its source regions. The combined $\mathrm{Rb}$ $\mathrm{Sr}$ and $\mathrm{Sm}-\mathrm{Nd}$ isotopic composition of the bulk sedimentshas been used to decipher the sediment source in Ghaggar alluvium. The $\mathrm{Sr}-\mathrm{Nd}$ isotopic compositions of different lithotectonic units of Himalaya is well-characterised (Najman, 2006 and the references therein) and it is presented in Fig. 4.

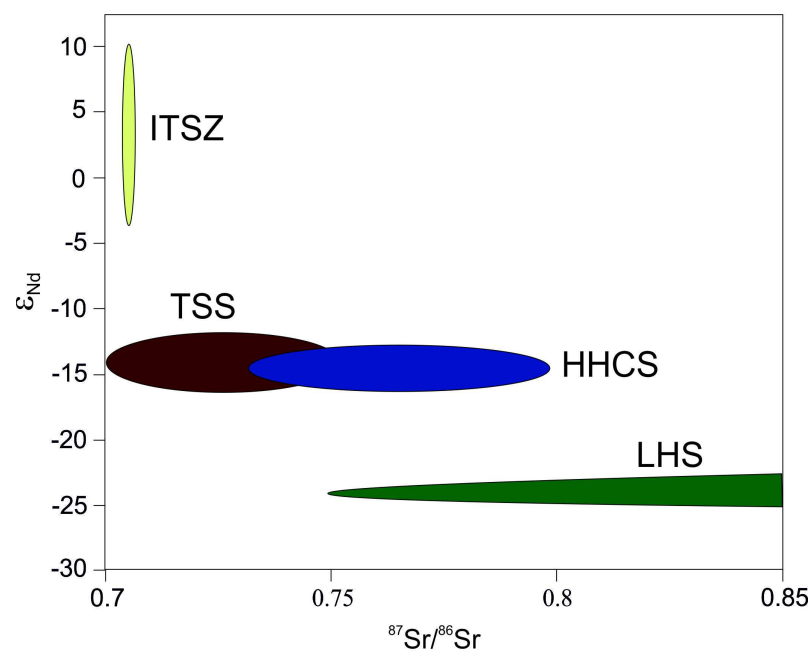

Fig. 4: Sr-Nd isotopic compositions of various Himalayan litho-tectonic units (modified from Najman, 2006)

The glaciated region of the Himalayas is made up of the Higher Himalayan Crystalline Series (HHCS) rocks and Lesser Himalayan Series (LHS) rocks. Himalayan glacial rivers carry sediments originated in these two sources and show a mixed signal. In Fig. 5, the Sr-Nd isotopic signals of Ghaggar alluvium with that of the sub-Himalayan lithologies and higher-Himalayan river derived sediments have been compared. The grey micaceous sands $(>20 \mathrm{ka})$ encountered in the Ghaggar alluvium have high radiogenic $\mathrm{Sr}$ and low $\mathrm{e}_{\mathrm{Nd}}$ (Singh et al., 2016). The Sr-Nd values of the grey sand deposits overlap with the range of values shown by sediments in most Himalayan glacier fed rivers. This on the other hand, suggests a provenance in the glaciated Himalayas. It can be observed that these grey sands were derived from a mixed HHCS and LHS sources. However, the younger deposits of grey sands reported by Saini et al. (2009) are not characterised geochemically. Therefore, there provenance is not known. Nevertheless, it is clear that these deposits represent bed load sediments indicating a stronger fluvial activity during that time.

The other two facies (brown coloured silty-clay and the yellowish-brown sand) of the Ghaggar alluvium shows distinctly different $\mathrm{Sr}-\mathrm{Nd}$ isotopic values than that of the grey sand (Fig. 5). This implies

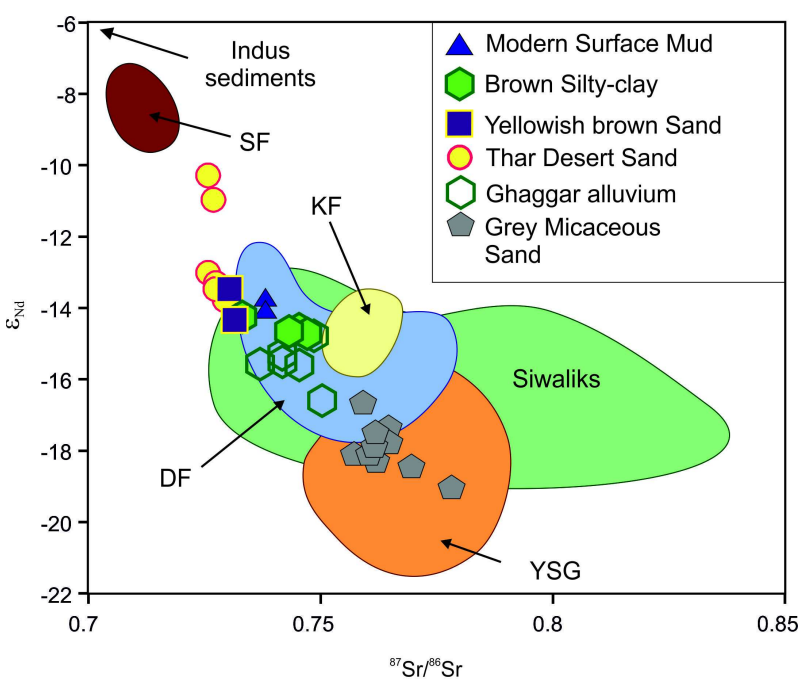

Fig. 5: $\mathrm{e}_{\mathrm{Nd}}$ vs. ${ }^{87} \mathrm{Sr} /{ }^{86} \mathrm{Sr}$ diagram representing the $\mathrm{Sr}-\mathrm{Nd}$ isotopic compositions of various sedimentary facieses in the Ghaggar alluvium compared with different sub-Himalayan litho-units and the sediments from the glaciated rivers. source: Chatterjee and Ray, (2018)

that the provenance of the formers is different from that of the Higher-Himalaya originated grey sands. These sediments show lower ${ }^{87} \mathrm{Sr} /{ }^{86} \mathrm{Sr}$ and higher $\mathrm{e}_{\mathrm{Nd}}$ ratios with respect to the grey micaceous sand. The modern Ghaggar river originatesfrom the subHimalayan Siwalik Group, Kasauli, Dagsahi and Subathu formations and is expected to carry sediments originated from these formations. Sr-Nd isotopic compositions of these lithologies can be seen in Fig. 5. The observations imply that the Subathu formation has very little influence in the Ghaggar sediment budget. The Siwalik Group, Kasauli and Dagsahi Formation are probably the major sources for the brown mud and yellowish-brown sand facies.

The Sr-Nd isotopic signals of Ghaggar alluvium 
strongly suggests that Himalayan glacier-fed paleoriver/s used to deliver sediments into the present day dry ephemeral river channel of Ghaggar during various periods in the past. However, Ghaggar river basin itself has no evidence of direct connection to the glaciated Higher Himalayas. Therefore, the Higher Himalayan sediments could have reached the Ghaggar alluvium only through the neighbouring Sutlej and Yamuna rivers. But, the Yamuna river had shifted from the Ghaggar channel 40 - 45 kyrs ago (Clift et al., 2012). Therefore, Sutlej becomes the only possible source. In fact, Mehdi et al. (2016) in their recent works have identified several paleo-channelswhich used to connect the present day Sutlej with the Ghaggar channel (Singh et al., 2017) and this connection was active till/during $9 \mathrm{ka}$. More geochemical and geochronological works have to be done for quantifying the provenance of the younger phase (mid-Holocene) of fluvial activities. This will further clarify whether there was any glacial connection to the Ghaggar river during the Holocene.

\section{Sedimentary Facies and Provenance of Hakra alluvium}

The downstream extension of the Ghaggar river in the Cholistan desert is known as Hakra. The course of the Hakra river vanishes into the desert dunes further downstream. The Hakara phase of Harappan culture wasfirst reported from this part of the paleoriver (Mughal, 1997). The main work involving provenance analysis from this part of the river was carried outby Clift et al. (2012).

\section{Facies Architecture and Sediment Depositional Ages of Hakra Valley}

Figure 6A represents the sampling locations and general stratigraphy from the study by Clift et al. (2012). They have reported a number of thick fluvial sand bodies. These sand bodies represent deposition in significant river channels. The thinner bedded sand bodies in alteration with the clay horizons most probably represent over bank sand deposits.

The major channels were active before $7.3 \mathrm{ka}$ at Marot and $5 \mathrm{ka}$ at Tilwalla region. Tilwalla region witnessed the last fluvial activity at $4.9 \mathrm{ka}$. However, just downstream of Ghaggar at Fort Abbas region such fluvial activity is reported until5.7 ka. Overlying sand dunes in this region gave an OSL deposition age of $1.4 \mathrm{ka}$. Therefore, it can be inferred that a number of fluvial channels existed along the present-day course of Hakra during the mid-Holocene. However, the largest channels were probably active during $49 \mathrm{ka}$.

\section{Tracing the Source of Sediments in the Hakra Valley}

For tracking the sediment provenance in the Hakra valley $\mathrm{U}-\mathrm{Pb}$ ages of detrital zircon grains have been used as tool (Alizai et al., 2011; Clift et al., 2012). The U-Pb age of a zircon crystal represents the time when it cooled below $750^{\circ} \mathrm{C}$. Due to the diachronous evolution of the Himalayas; zircon ages varies in different parts of Himalayas and they can be used as good provenance proxies (DeCelles, 2000). Following are the different age ranges of zircons available in various Himalayan lithotectonic units. Karakoram and Trans Himalaya: 0-300Ma, Tethyan Himalaya: 300$750 \mathrm{Ma}$, Tethyan and Higher Himalaya: 750-1250 Ma, Lesser Himalaya: 1500-2300 Ma.

The sand horizon lying on top of the $43 \mathrm{ka}$ old sand of Tilwalla have a major population of 300-750 Ma zircons (39\% of total). Only the Beas river is known to carry this age group of zircons inmajority (61\%). Therefore, it can be said that, during the maximum fluvial activity around 40ka Hakra channel was receiving water from the Beas river at Tiwalla (Fig. 6B). This requires Sutlej to flow further east of the Beas-Hakra confluence and meet the Hakra upstream (Fig. 6B). In the oldest deposits of Marot region $(>49 \mathrm{ka})$ the zircon population aging $300-750 \mathrm{Ma}$ are much less (17\%) than Tilwalla. Rather these sands are dominated with zircon population of 1500-2300 Ma age, representing Lesser Himalayan sources. Similar age population zircons are common in the modern sediments of Sutlej and Yamuna. However, statistically zircon population of Yamuna sediment are more similar to those of the older Marot sediments. Therefore, it can be inferred that Hakra was receiving water from the Yamuna river in the Marot region before $49 \mathrm{ka}$ (Fig. 6B). Towards the top of this massive sand deposit (just above the $>49 \mathrm{ka}$ OSL age) zircons show more similarity with the Sutlej sediments. This implies that, Yamuna started shifting from Hakra channel during this time and Sutlej started dominating the sedimentation. However, the zircon population of 6ka old fluvial deposits at Marot region show resemblance towards the zircon populations of Thar 


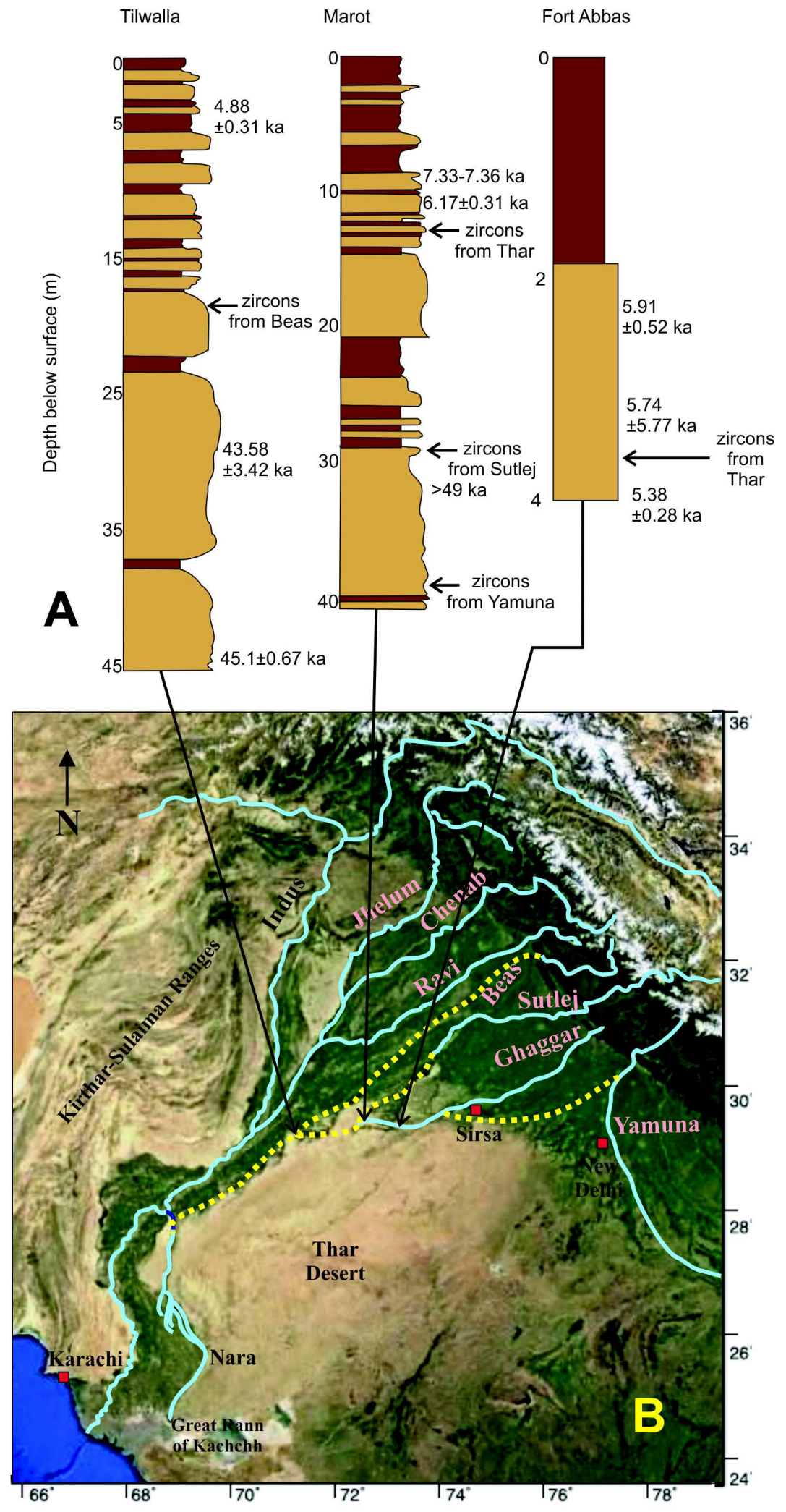

Fig. 6: (A) Facies architecture of the Hakra alluvium (modified from Clift et al., 2012). (B) Google earth map showing the locations in the Hakra alluvium from where the stratigraphy had been developed. The yellow dotted lines are probable condition of the rivers during Pleistocene as presented by (Clift et al., 2012) desert. So, probably by this time the river lost its glacial sources and started depositing locally reworked sands. The 5.7 ka old fluvial sands at Fort Abbas however, show affinity to the Thar desert implying no major glacier river in this region during the mid-Holocene.

\section{Sedimentary Facies and Provenance of Nara alluvium}

The Nara river is a defunct channel which used to drain in to the Great Rann of Kachchh. At present it receives water only during the monsoonal overflow in the Indus River via a man-made canal.It was considered by many workers to be the downstream continuation of the Ghaggar-Hakra river (Glennie and Evans, 1976; Malik et al., 1999). In this context the Nara river and the Great Rann of Kachchh(the purported delta of the river) becomes an important piece of our lost river puzzle. Until recently, there were not much work which involved the sediment provenance study of Nara valley and the GRK.

\section{Facies Architecture and Sediment Depositional Ages of Nara Valley and Great Rann of Kachchh}

In their recent work Tyagi et al. (2012) have demonstrated that the western GRK (Nara meets the GRK at this part) is dominated by tidal environment since midHolocene except for a little fluvial influence in the vicinity of Nara. This debunks the existence of any major fluvial system active along the Nara river during this period. Their studies as well as other works in the Nara valley (Alizai et al., 2011; Ngangom et al., 2012) shows that the Nara valley is dominated by fine grained silty sediments with occurrences of sandy horizons in between. These 
sandy horizons represent fluvial activities along the channel. The available depositional ages indicate that the fluvial sedimentation was active all along the Holocene in small phases as young as 700 years ago (Alizai et al., 2011; Giosan et al., 2012; Ngangom et al., 2012; Tyagi et al., 2012). Figure 7 represents the stratigraphy and depositional ages observed in the Nara valley and western GRK during the Holocene.

\section{Sediment Provenance of the Nara Valley and the Great Rann of Kachchh}

In spite of its association with the mythical lost river, only a few attempts have been taken to decipher the sediment provenance of the Nara valley. Alizai et al. (2011) first approached this problem with the geochemical characterisation of detrital mineral. They have used the $\mathrm{Pb}-\mathrm{Pb}$ isotopic compositions of detrital $\mathrm{K}$-feldspars as a tool to understand whether the sediments within the Nara valley weredeposited by an independent river flowing from the north (the Ghaggar-Hakra river). They were able to show that the sediments within the Nara valley were sourced mainly from the Himalayas. However, influence from the trans-Himalayan sources (carried by Indus) is also there. Moreover, the $\mathrm{Pb}$-isotopic composition of the K-feldspars recovered from the Nara valley overlaps with that of the K-feldspar from Sutlej, Chenab and Indus (downstream at Sukkur). Consequently, it was not possible to distinguish between the Indus derived sediments and northern river derived sediments using this tool. However, their work showed that there was only little influence from the local sand dunes into the Nara river deposit.

Indirect evidence for the sediment provenance in this part of the sub-continent comes from the clay mineral studies (Khonde et al., 2017) of the southern part of GRK. Earlier, it was considered that the sediments in the GRK were derived from the Indus via storm tides through the tidal creeks. In their study Khonde et al. (2017) tested this hypothesis and collected samples from cores raised from the GRK. The major clay minerals observed were Illite, Chlorite, Smectite and Kaolinite. They have shown that the GRK sediments have very different clay mineral composition than that of the Indus sediments. Illite is the most dominant mineral in the GRK. Illite is the dominant mineral phase in the Indus valley as well as eastern Punjab plains. However, in GRK sediments

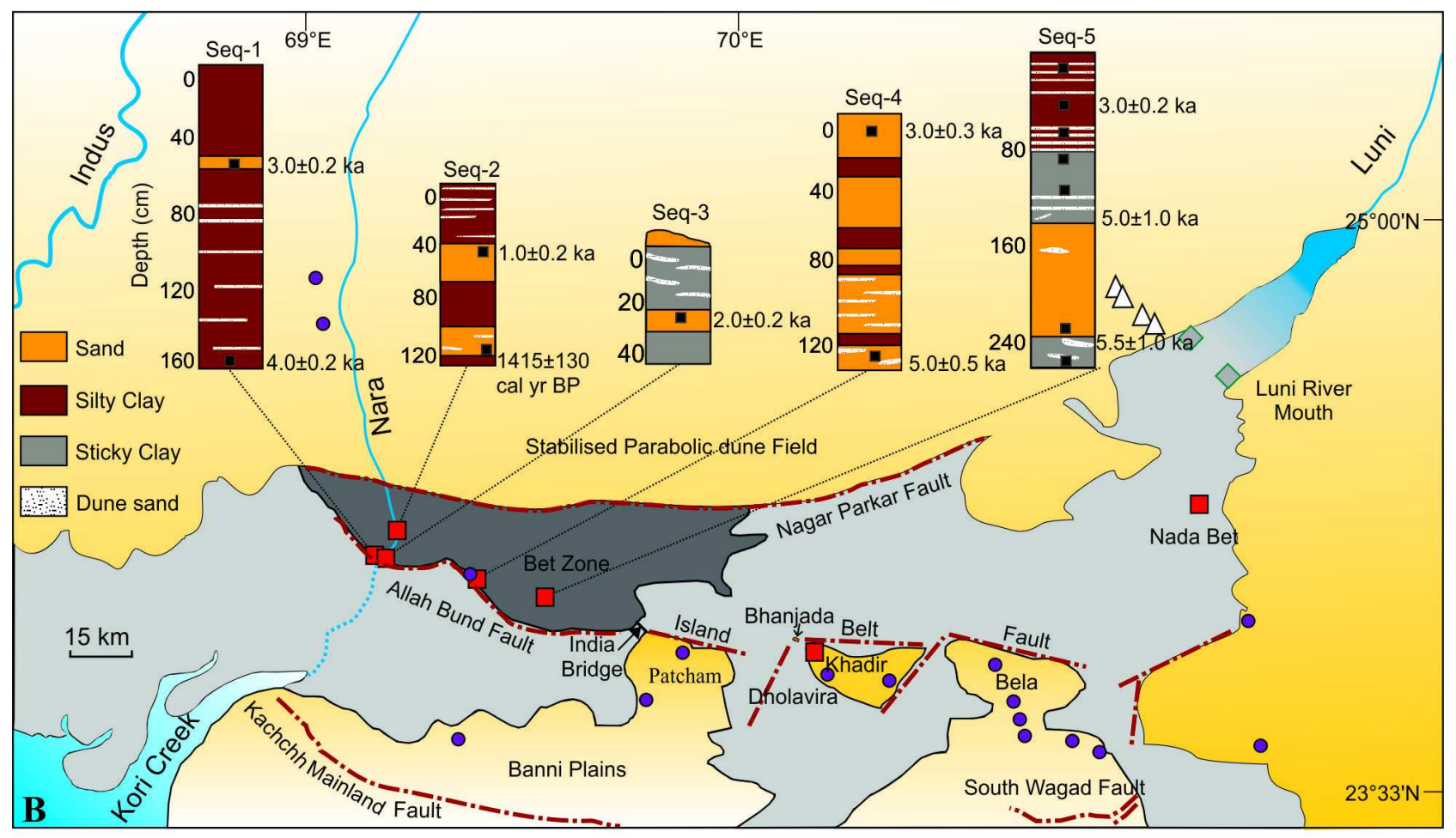

Fig. 7: Schematic sketch map of the Great Rann of Kachchh, showing the major geomorphological features, sedimentary facies architecture and the sampling locations (modified from Chatterjee and Ray, 2017) 
Illite concentrations are much more (62\%) than any other sources. Illite is mainly considered to be sourced from the Himalayas. Indus sediments are also dominated with Smectite which is considered to be derived from juvenile rocks. This means that the smectite in the Indus sediments is mainly derived from the weathering of trans-Himalayan suture zone rocks. However, in the GRK sediments Smectite is not much abundant with respect to that of the Indus sediments. Instead, GRK sediments have much more Chlorite concentration. Chlorite on the other hand is considered to be derived from physical weathering in cold and dry climate indicating a probable Himalayan source. More kaolinite concentration in the GRK sediments than the Indus sediments definitely indicate input from the local Mesozoic rocks. However, excess Illite and Chlorite concentration in the GRK sediments definitely indicates that there was a separate Himalayan source into the GRK than Indus. In that case, Nara becomes the best possible candidate to carry the Himalayan sediments into the GRK.

Another recent geochemical study conducted by Chatterjee and Ray (2017) deals with the sediment provenance of the western Great Rann of Kachchh. The study used trace element geochemistry and Sr$\mathrm{Nd}$ isotopic fingerprinting as a tool for provenance. The trace element geochemistry of the GRK sediments indicated that they were not solely derived from the Indus river. Rather they have mix signal between the Indus derived sediments, Thar sand and sediments from the rivers of Punjab (Chatterjee and Ray, 2017). A three-component mixing grid in the $\mathrm{e}_{\mathrm{Nd}}$ vs. ${ }^{87} \mathrm{Sr} /{ }^{86} \mathrm{Sr}$ diagram involving the major Himalayan sources indicates that the sediments deposited in the GRK since mid-Holocene are mainly dominated by Indus river sediments (Fig. 8A). However, Indus alone cannot explain the relatively

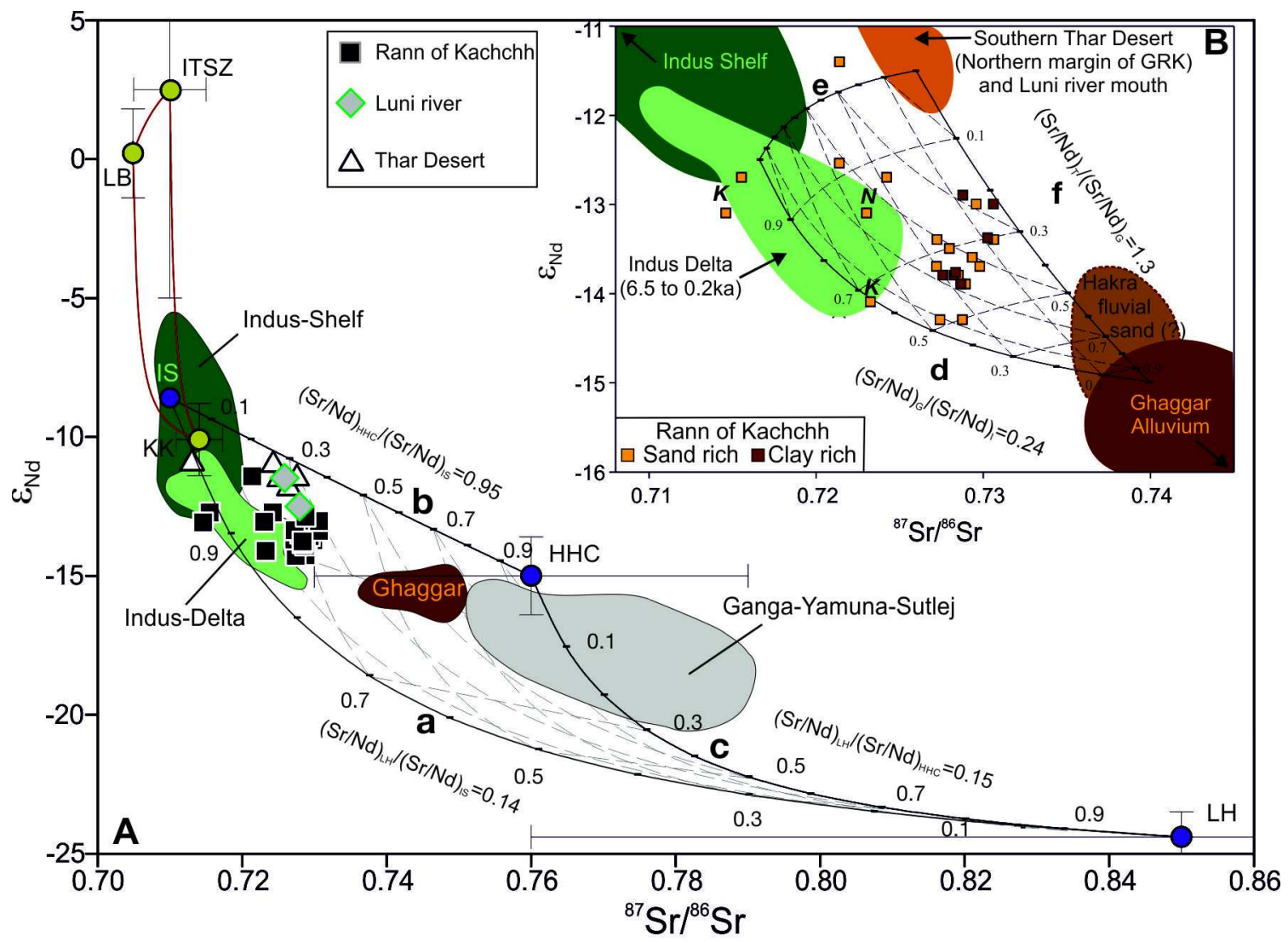

Fig. 8: (A) A ternary mixing grid within the $\mathrm{e}_{\mathrm{Nd}}$ vs. ${ }^{87} \mathrm{Sr} /{ }^{86} \mathrm{Sr}$ plot involving the end members: IS (Indus at Skardu), HHC (Higher Himalayan Crystalline), and LH (Lesser Himalaya). The GRK sediments, Ganga-Yamuna-Sutlej sediments, Ghaggar sediments and Indus river sediments are also plotted. (B) A ternary mixing diagram for quantifying the contribution of the probable sediment sources (Indus sediment, Thar desert and Ghaggar/Hakra sediments) into the GRK. Both the figures are modified from Chatterjee and Ray (2017) 
higher radiogenic $\mathrm{Sr}$ in the GRK sediments. The local sources (like the Luni river sediment, Thar desert sediment etc.) can neither explain the isotopic composition of the GRK sediments. In a detailed mixing grid involving the potential sediment sources for the GRK (Fig. 8B) shows that the GRK sediments have a significant component of Ghaggar sediments $(\sim 20-30 \%)$ in them. Considering the fact that these sediments were depositing up to $\sim 1 \mathrm{ka}$, it is clear that the Ghaggar-Hakra-Nara channel was a continuous one until historic times. However, existence of a glacier fed river active along this channel during the midHolocene was not found in this study. Rather, the river appeared to be a rain-fed monsoonal river during that period.

From this discussion, it is clear that the sedimentation in the GRK as well as in the Nara valley cannot be explained solely by the sedimentation in the Indus river system. There must have been another independent drainage system which carried the Himalayan sediments into the GRK. However, further detailed study on sediment provenance is needed to confirm the existence of a Himalayan paleo-river draining into the GRK via Nara channel during Holocene.

\section{Summary}

From the above discussion it is clear that there existed a major glacier fed river system independent of the Indus river, flowing along the present day discontinuous Ghaggar-Hakra-Nara channels.

\section{References}

Alizai A, Carter A, Clift P D, VanLaningham S, Williams J C and Kumar R (2011) Sediment provenance, reworking and transport processes in the Indus River by $\mathrm{U}-\mathrm{Pb}$ dating of detrital zircon grains Glob Planet Change 76 33-55

Chatterjee A and Ray J S (2016) Evidence for a Mid-Holocene Buried Himalayan River beneath the Ghaggar Plains, NW India: A Geochemical Provenance Study. Abstract submitted to the Goldschmidt Conference, Yokohama, Japan, 2016. Online available at : https://goldschmidt abstracts.info/abstracts/abstractView?id= 2016002333

Chatterjee A and Ray J S (2017) Sources and depositional
However, as per our present understanding its existence cannot be confirmed unambiguously during the Holocene. There are evidence of fluvial activities all along the Ghaggar-Hakra-Nara alluvium during the Holocene period. The problem resides with the origin of sediments during that period. The works at the Hakra reach of the river system indicates that these young fluvial sediments deposited during Holocene were mainly derived locally.

This indicates that during the Holocene, the Hakra system was not receiving any water from glacier sources. Rather, the river was an ephemeral rain-fed system. This analogy however cannot justify the fluvial deposits of mid-Holocene Ghaggar alluvium in the upstream Sirsa-Fatehbad region. Although, the young sand horizons reported from these regions are not characterised geochemically, they resemble to the sediments deposited by the glacier fed rivers. Also, the studies from the Nara valley as well as GRK clearly implies that the Ghaggar-Hakra-Nara was a continuous river channel until historical time $(\sim 1 \mathrm{ka})$ and used to deliver sediment into the GRK. However, this review of the recent works confirms that before the peak of the Harappan period ( 4.6 ka) the Ghaggar-Hakra-Nara system lost its glacial sources and became a foothill-fed river system. The river during the mature Harappan period might have been sustained by several other rain-fed tributaries. On the other hand, more investigations are needed to accurately characterise the river system during the early Holocene and how the evolving river system affected the evolution of the Early Harappan.

pathways of mid-Holocene sediments in the Great Rann of Kachchh, India: Implications for fluvial scenario during the Harappan Culture Quat Int 443 177-187. doi:10.1016/ j.quaint.2017.06.008

Chatterjee A (2017) Provenance of Late Quaternary Continental Sediments in WesternIndia: Insights from Trace Element and Isotope Geochemistry. PhD thesis, The Maharaja Sayajirao University of Baroda, Vadodara, online at : https:/ /shodhganga.inflibnet.ac.in/handle/10603/199906

Chatterjee A and Ray J S (2018) Geochemistry of Harappan Potteries from Kalibangan and sediments in the Ghaggar River: Clues for a Dying River Geosci Front 9 1203-1211 doi:10.1016/j.gsf.2017.07.006 
Clift P D, Carter A, Giosan L, Durcan J, Duller G A T, Macklin M G, Alizai A, Tabrez A R, Danish M, VanLaningham S and Fuller D Q (2012) U-Pb zircon dating evidence for a Pleistocene Sarasvati River and capture of the Yamuna River Geology 40 211-214. doi:10.1130/G32840.1

Danino M (2010) The Lost River - On the trail of the SARASVATI. Penguin Books

DeCelles P G (2000) Tectonic Implications of U-Pb Zircon Ages of the Himalayan Orogenic Belt in Nepal Science $288497-$ 499. doi:10.1126/science.288.5465.497

Dikshit K N (2013) Origin of Early Harappan cultures in the Sarasvati Valley: Recent Archaeological Evidence and Radiometric dates J Indian Ocean Archeol 9 87-141

Gangal K, Vahia M N and Adhikari R (2010) Spatio-temporal analysis of the Indus urbanisation Curr Sci 98 846-852

Ghose B, Kar A and Husain Z (1979) The lost courses of the Saraswati River in the Great Indian Desert: new evidence from Landsat imagery Geogr $J 145$ 446-451

Giosan L, Clift P D, Macklin M G, Fuller D Q, Constantinescu S, Durcan J, Stevens T, Duller G A T, Tabrez A R, Gangal K, Adhikari R, Alizai A, Filip F, VanLaningham S and Syvitski J P M (2012) Fluvial landscapes of the Harappan civilization Proc Natl AcadSci U S A 109 E1688-94. doi:10.1073/pnas.1112743109

Glennie K W and Evans G (1976) A reconnaissance of the Recent sediments of the Ranns of Kutch, India Sedimentology 23 625-647

Gupta A K, Sharma J R and Sreenivasan G (2011) Using satellite imagery to reveal the course of an extinct river below the Thar Desert in the Indo-Pak region Int J Remote Sens 32 $5197-5216$

Kenoyer J M (1998) Ancient Cities of the Indus Valley Civilization. Oxford University Press: Oxford

Kenoyer J M (2008) Indus Civilization. In: Encyclopedia of Archaeology. Elsevier, New York, pp. 715-733

Khonde N, Maurya D M and Chamyal L S (2017) Late Pleistocene-Holocene clay mineral record from the Great Rann of Kachchh basin, Western India: Implications for palaeoenvironments and sediment sources Quat Int $\mathbf{4 4 3}$ 86-98 doi:10.1016/j.quaint.2016.07.024

Kochar R (2000) Vedic People: Their History and Geography. Orient Longman, Hyderabad

Malik J N, Merh S S and Sridhar V (1999) Palaeo-delta complex of Vedic Saraswati and other ancient rivers of north-western India Mem Geol Soc India 42 163-174

Mehdi M, Pant N C, Saini H S and Mujtaba S A I (2016) Identification of palaeochannel configuration in the
Saraswati River basin in parts of Haryana and Rajasthan, India , through digital remote sensing and GIS Episodes 39 1-10. doi:10.18814/epiiugs/2016/v39i1/XXXXX

Mughal M R (1997) Ancient Cholistan: Archaeology and architecture. Ferozsons, Lahore, Pakistan

Najman Y (2006) The detrital record of orogenesis: A review of approaches and techniques used in the Himalayan sedimentary basins Earth-Science Rev 74 1-72 doi:10.1016/ j.earscirev.2005.04.004

Ngangom M, Thakkar M G, Bhushan R and Juyal N (2012) Continental - marine interaction in the vicinity of the Nara River during the last 1400 years, Great Rann of Kachchh, Western India Curr Sci 103 1339-1342

Oldham C F (1893) The Saraswati and the lost river of the Indian desert $J R$ Asiat Soc 34 49-76

Pal Y, Sahai B, Sood R K and Agarwal D P (1980) Remote sensing of the "Lost" Saraswati river Proceeding Indian Natal Sci Acad (Earth and Planetry Sci) 89 317-331

Possehl G L (2002) The Indus Civilization: A contemporary perspective. AltaMira Press, Lanham, Maryland

Radhakrishan B P and Merh S S (1999) Vedic Sarasvati: Evolutionary History of a Lost River of Northwestern india Memo Geol Soc India 42 5-13

Raikes R (1968) Kalibangan: Death from Natural Causes Antiquity XLII 286-291

Saini H S and Mujtaba S A I (2012) Depositional history and palaeoclimatic variations at the northeastern fringe of Thar Desert, Haryana plains, India Quat Int 250 37-48 doi:10.1016/j.quaint.2011.06.002

Saini H S, Tandon S K, Mujtaba S A I, Pant N C and Khorana R K (2009) Reconstruction of buried channel-floodplain system of the northwestern Haryana Plains and their relation to the 'Vedic' Saraswati Curr Sci 97 1634-1643

Sarkar A, Mukherjee A D, Bera M K, Das B, Juyal N, Morthekai P, Deshpande R D, Shinde V S and Rao L S (2016) Oxygen isotope in archaeological bioapatites from India: Implications to climate change and decline of Bronze Age Harappan civilization Sci Rep 626555 doi:10.1038/ srep26555

Singh A, Paul D, Sinha R, Thomsen K J and Gupta S (2016) Geochemistry of buried river sediments from Ghaggar Plains, NW India: Multi-proxy records of variations in provenance, paleoclimate, and paleovegetation patterns in the Late Quaternary Paleogeogr, Paleoclimatol, Paleoecol 449 85-100 doi:http://dx.doi.org/10.1016/ j.palaeo.2016.02.012

Singh A, Thomsen K J, Sinha R, Buylaert J, Carter A, Mark D F, 
Mason P J, Densmore A L, Murray A S, Jain M, Paul D and Gupta S (2017) Counter-intuitive influence of Himalayan river morphodynamics on Indus Civilisation urban settlements Nat Commun 81617 (2017) doi:10.1038/ s41467-017-01643-9

Sinha R and Friend P F (1994) River systems and their sediment flux, Indo Gangetic plains, Northern Bihar, India Sedimentology 41 825-845

Stein A (1942) A survey of ancient sites along the lost Saraswati river Geogr J 99 173-182

Tripathi J K, Bock B, Rajamani V and Eisenhauer A (2004) Is River Ghaggar, Saraswati? Geochemical constraints Curr Sci 87 1141-1145
Tyagi A K, Shukla A D, Bhushan R, Thakker P S, Thakkar M G and Juyal N (2012) Mid-Holocene sedimentation and landscape evolution in the western Great Rann of Kachchh, India Geomorphology 151 89-98 doi:10.1016/j.geomorph. 2012.01.018

Valdiya K S (2013) The River Saraswati was a Himalayan-born river Curr Sci 104 42-54

Valdiya K S (2017) Prehistoric River Saraswati, Western India Geological Appraisal and Social Aspects. Springer.

Wright R P, Bryson R A and Schuldenrein J (2008) Water supply and history/: Harappa and the Beas regional survey Antiquity 82 37-48. 